\title{
White matter lesions in cerebral small vessel disease
}

\section{Underperfusion or leaky vessels?}

Atticus H. Hainsworth, PhD

Neurology ${ }^{\circledR} 2019 ; 92: 1-2$. doi:10.1212/WNL.0000000000007258

T2-weighted MRI brain scans in older people commonly reveal diffuse white matter hyperintensities (WMH). These changes often accompany focal, lacunar ischemic lesions and likely constitute a feature of sporadic small vessel disease (SVD). ${ }^{1}$

SVD affects the small penetrating arteries (outer diameter usually $<0.2 \mathrm{~mm}$ ) that supply deep brain areas. SVD is a common age-related cerebral vasculopathy, ${ }^{2,3}$ possibly the most common. Often associated with high blood pressure, SVD leaves vessels with thickened, fibrotic walls that are depleted of myocytes. ${ }^{1}$ In the absence of longitudinal experimental models, any theory of WMH formation will prove difficult to verify. One theory (Theory A) posits that a loss of vessel contractility and impaired autoregulation of local cerebral blood flow $(\mathrm{CBF})$ over a chronic timescale may lead to cumulative hypoperfusion lesions in the downstream territory. This plausible explanation for the formation of WMH is supported by imaging-based measurements of regional CBF. ${ }^{4,5}$

Another possible explanation (Theory B) suggests that pathologic changes in the small artery wall lead to dysfunction in the blood-brain barrier (BBB) locally and in the downstream capillary bed. The main evidence supporting this theory comes from MRI analyses in human patients, using regional accumulation of an intravascular contrast agent as a marker for areas with a leaky BBB. ${ }^{6,7}$ Multiple groups have detected higher abundance of contrast agent in people with SVD relative to controls. ${ }^{6-8}$ Further, patients with SVD exhibit more contrast agent within WMH relative to spatially distinct, nonhyperintense white matter that appears normal on MRI (normal-appearing white-matter [NAWM] $).{ }^{6-8}$ Neuropathologic data have not universally supported these MRI findings. ${ }^{9}$ Because hypoperfusion can cause BBB leakiness and fluid extravasation can lead to edema and impaired blood flow, separating these 2 theories experimentally poses substantial challenges. In the clinical context of an aged human brain, these processes may well be interlinked, a concept supported by a report in this issue of Neurology ${ }^{\circledR}$ by Wong et al. ${ }^{10}$ from the Maastricht University Medical Center.

The authors studied 27 older patients aged 69 (12) years (mean [SD]) diagnosed clinically either with a lacunar stroke event or with vascular cognitive impairment, the salient clinical manifestations of SVD. Following injection of gadolinium-based contrast agent, they used dynamic susceptibility contrast MRI to quantify regional CBF and a dynamic contrast enhancement MRI sequence to map regional BBB permeability. ${ }^{10}$

Local blood flow (in $\mathrm{mL} / \mathrm{min} / 100 \mathrm{~g}$ of tissue) was $0.74 \times$ lower within WMH than in NAWM, consistent with Theory A. Contrast agent leakage volume (a measure of the physical extent of leakage) was $1.16 \times$ higher within WMH than in NAWM, consistent with Theory B. Local CBF correlated negatively with leakage volume and with leakage rate, both in NAWM and in WMH $\left(R^{2}<0.29\right)$. The correlation between local CBF and local leakage rate grew stronger in the socalled perilesional zone, around and just outside the perimeter of $\mathrm{WMH}$, relative to bulk NAWM. ${ }^{10}$ These authors and others ${ }^{8}$ make the reasonable assumption that in expanding WMH this is likely to be a pathologically interesting area. In this perilesional zone, where tissue

\author{
Correspondence \\ Dr. Hainsworth \\ ahainsworth@sgul.ac.uk
}

\section{RELATED ARTICLE}

Blood-brain barrier

impairment and

hypoperfusion are linked in cerebral small vessel disease Page 700 
changes are likely to be occurring but tissue is not yet hyperintense, they speculate that insufficient blood flow and impaired $\mathrm{BBB}$ are both part of the pathologic process. The authors are careful to step back from inferring a causal link of $\mathrm{CBF}$ to $\mathrm{BBB}$ dysfunction or vice versa. ${ }^{10}$

The authors have packaged these intriguing findings in a careful quantitative study. There clearly are limitations. First and most notably, they have used a relatively small, convenience cohort, derived from one clinical service. Second, they did not consider the likely relevant effects of other age-related brain pathologies. Neuropathologic assessments of large populations indicate that cerebrovascular pathologies and Alzheimer disease $(\mathrm{AD})$ pathology are more usually found together than apart. ${ }^{2,3} \mathrm{WMH}$ are seen in people with clinical and neuropathologic $\mathrm{AD}$ diagnosis and also in cognitively healthy older people. Those WMH may result from comorbid SVD or they may not. The interactions of local blood flow, $\mathrm{BBB}$ dysfunction, and $\mathrm{AD}$-related pathology are likely to be interestingly complicated, and relevant to clinical realities. Dissecting these interactions will benefit from deeper molecular understanding of what WMH really are.

\section{Study funding}

No targeted funding reported.

\section{Disclosure}

A.H.H. has funding from UK MRC (MR/R005567/1), Alzheimer's Society (UK), and ADDF (Ref. 20140901); has received honoraria from Eli Lilly and the NIA; and is part of the Dementia Platform UK Vascular Experimental Medicine group. Go to Neurology.org/N for full disclosures.

\section{References}

1. Jorgensen DR, Shaaban CE, Wiley CA, Gianaros PJ, Mettenburg J, Rosano C. A population neuroscience approach to the study of cerebral small vessel disease in midlife and late life: an invited review. Am J Physiol Heart Circ Physiol 2018;314: H1117-H1136.

2. Kapasi A, DeCarli C, Schneider JA. Impact of multiple pathologies on the threshold for clinically overt dementia. Acta Neuropathol 2017;134:171-186.

3. Savva GM, Wharton SB, Ince PG, Forster G, Matthews FE, Brayne C. Age, neuropathology, and dementia. N Engl J Med 2009;360:2302-2309.

4. O'Sullivan M, Lythgoe DJ, Pereira AC, et al. Patterns of cerebral blood flow reduction in patients with ischemic leukoaraiosis. Neurology 2002;59:321-326.

5. Marstrand JR, Garde E, Rostrup E, et al. Cerebral perfusion and cerebrovascular reactivity are reduced in white matter hyperintensities. Stroke 2002;33:972-976.

6. Topakian R, Barrick TR, Howe FA, Markus HS. Blood-brain barrier permeability is increased in normal-appearing white matter in patients with lacunar stroke and leucoaraiosis. J Neurol Neurosurg Psychiatry 2010;81:192-197.

7. Heye AK, Thrippleton MJ, Armitage PA, et al. Tracer kinetic modelling for DCE-MRI quantification of subtle blood-brain barrier permeability. Neuroimage 2016;125: 446-455.

8. Huisa BN, Caprihan A, Thompson J, Prestopnik J, Qualls CR, Rosenberg GA. Longterm blood-brain barrier permeability changes in Binswanger disease. Stroke 2015;46: 2413-2418.

9. Hainsworth AH, Minett T, Andoh J, et al. Neuropathology of white matter lesions, blood-brain barrier dysfunction, and dementia. Stroke 2017;48:2799-2804.

10. Wong S, Jansen FA, Zhang E, et al. Blood-brain barrier impairment and hypoperfusion are linked in cerebral small vessel disease. Neurology 2019;92:e1669-e1677. 


\title{
Neurology
}

\author{
White matter lesions in cerebral small vessel disease: Underperfusion or leaky vessels? \\ Atticus H. Hainsworth \\ Neurology published online March 13, 2019 \\ DOI 10.1212/WNL.0000000000007258
}

This information is current as of March 13, 2019

\begin{abstract}
Updated Information \& Services

including high resolution figures, can be found at: http://n.neurology.org/content/early/2019/03/13/WNL.0000000000007 258.full

Subspecialty Collections

This article, along with others on similar topics, appears in the following collection(s):

All Cerebrovascular disease/Stroke e

MRI

http://n.neurology.org/cgi/collection/mri

Permissions \& Licensing its entirety can be found online at:

http://www.neurology.org/about/about_the_journal\#permissions

Reprints Information about ordering reprints can be found online:

http://n.neurology.org/subscribers/advertise
\end{abstract}

http://n.neurology.org/cgi/collection/all_cerebrovascular_disease_strok

Information about reproducing this article in parts (figures,tables) or in

Neurology ${ }^{\circledR}$ is the official journal of the American Academy of Neurology. Published continuously since 1951, it is now a weekly with 48 issues per year. Copyright () 2019 American Academy of Neurology. All rights reserved. Print ISSN: 0028-3878. Online ISSN: 1526-632X.

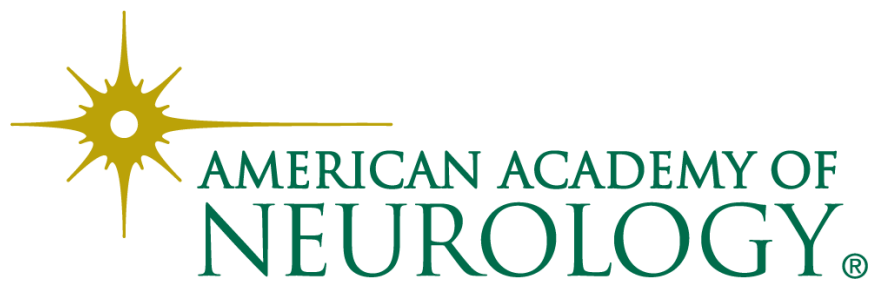

